\title{
Simple Approach to Bandwidth Enhancement of Compact Pifa for Wireless System Applications
}

\author{
Ikechiamaka F. $\mathbf{N}^{* 1}$, Akinbolati $\mathbf{A}^{2}$, Okpala $C^{3}$ \\ 1,2,3Federal University Dutsin - Ma, Katsina State, Nigeria/Department of Physics, Faculty of \\ Physical Sciences \\ fosuagwu@fudutsinma.edu.ng*
}

\begin{abstract}
Bandwidth is a critical parameter that must be considered in the design of electrically small antennas for compact wireless system. In order to overcome the demerit of narrow bandwidth, a simple method of bandwidth enhancement through parametric study of PIFA is proposed. The PIFA understudied was designed and simulated by the use of theoretical equations based on transmission line model and High Frequency Structural Simulator (HFSS) respectively. It has initial bandwidth of $120 \mathrm{MHz}$. The study reveals that by reducing the size ratio of the planar element (radiating patch) of PIFA, bandwidth enhancement of $40.0 \%$ was achieved. Increasing the distance between short plate and feed gave rise to $55.0 \%$ increment in bandwidth while increasing the length of ground plane while keeping the width of ground plane constant enhanced bandwidth by $150.0 \%$. The designed compact PIFA of patch size $34 \mathrm{~mm} \times 17 \mathrm{~mm} \times 2 \mathrm{~mm}$ can be employed in wireless systems such as cell phone (GSM 900) and implantable medical devices(ISM 900).
\end{abstract}

Keywords: Bandwidth, PIFA, Parametric Study, Resonance Frequency

\section{Introduction}

A constant increase in the number of wireless communication standards being applied in mobile terminals has created the need for internal antennas operating at different frequency bands. Designing small and low profile internal antennas with a simple structure is a necessary challenge for the mobile phone industry. Phone manufacturers need to keep production costs low while continuing to produce devices with multiple standards. Thus, these devices need to accommodate an increasing number of antennas in a simultaneously decreasing available volume. According to the theory of fundamental physical limitations, it is a major challenge to make an antenna in the small available volume that covers a single very wide frequency band or multiple frequency bands with high total antenna efficiency [1]. Though recent mobile terminal antennas are mainly of wide-band and multiple band types, the multiple band operation is achieved at the expense of increased antenna size [2].

Planar inverted-F antennas (PIFAs) are electrically small and low profile antennas widely used in mobile terminals due to their small size, low cost and ease of design and manufacturing. Furthermore, PIFA with low specific absorption rate (SAR) can be easily fed and concealed in devices such as cell phone [3]. However, a major disadvantage of the PIFA antenna is its narrow impedance bandwidth [4]. Hence, it is desirable to find methods that can enhance the bandwidths of the PIFA antennas while maintaining the compact structure at reasonable cost. Several approaches described in recent times introduce some level of complexity in the design. The bandwidth of the PIFA is increased by using a tapered-type radiating patch and by introducing multi-layer patches and a folded stub into the internal PIFA [5]. It has also been reported that making modifications on the system ground plane of mobile terminals, for instance, use of $T$ shaped ground plane and a slotted ground plane can broaden the bandwidth of the PIFA antenna [6]. These methods of bandwidth improvement are complex to design, hence do not support the production of low cost devices. Other techniques that aid bandwidth enhancement include; capacitive loading of the patch, loading with high permittivity substrates, and attaching chip resistor [7]. Increase in bandwidth of PIFA by adding parasitic resonators to the main radiator and the use of external matching circuitry are described in [8]. The addition of parasitic resonators is especially suitable for increasing the bandwidth of higher frequency bands, because the required length of the additional resonators is shorter for providing an additional resonant mode at such

Ikechiamaka, F., A, A., \& C, O. (2019). Simple Approach to Bandwidth Enhancement of Compact Pifa for Wireless System Applications. Kinetik: Game Technology, Information System, Computer Network, Computing, Electronics, and Control, 4(2). doi:http://dx.doi.org/10.22219/kinetik.v4i2.737 
frequencies while the use of an external matching circuitry involves additional circuitry hence, miniaturization is not achieved.

In recent times, bandwidth enhancement of some compact PIFA has been reported in several researchers. Capacitive $\mathrm{U}-$ feed technique employed in the design of PIFA of volume $60 \mathrm{~mm} \times 30 \mathrm{~mm} \times 5 \mathrm{~mm}$ gave wide bandwidth at $1.66-2.84 \mathrm{GHz}$ and $3.36-3.64 \mathrm{GHz}$ [9]. A hook - shaped slot at radiating patch as well as a modified ground plane with a pair of square rings and a rotated I - shaped slots enhanced bandwidth of PIFA by $2-3$ percent at $3.3 \mathrm{GHz}$ and $5.2 \mathrm{GHz}$ frequencies [10]. Introduction of a slot on the radiator and ground in addition to the use of a shorting wall instead of pins at a well-chosen location broadened the bandwidth of PIFA of size $48.5 \times 19 \times 6.5 \mathrm{~mm}^{3}$ to about $200 \mathrm{MHz}$ for center frequency $2.92 \mathrm{GHz}$.[11].Improved bandwidth has been achieved by controlling current distribution through the implementation of two vias in a printed PIFA of dimension $100 \mathrm{~mm} \times 60 \mathrm{~mm} \times 1.6 \mathrm{~mm}$ that resonated between $1.2-3.0 \mathrm{GHz}[12]$. A single-wideband 3D PIFA with size $55 \mathrm{~mm} \times 20 \mathrm{~mm} \times 3 \mathrm{~mm}$ covering frequency band from around $1.6 \mathrm{GHz}$ to $3.6 \mathrm{GHz}$ in one single band was presented in scientific literature [13]. It was reported that besides the variations in the dimensions and positions of the shorting and feeding plates, additional method of insertion of slot in the ground plane was used to enhance the overall bandwidth of the directional antenna for Universal Serial Bus (USB) applications [13]. To overcome the narrow bandwidth of PIFA at lower microwave frequency band, Muneer and his colleagues considered design of PIFA for higher microwave frequency band of $3.0 \mathrm{GHz}-6.0 \mathrm{GHz}$. In this $2 \times 3$ array, 2 - layer PIFA of dimension $72 \times 62 \mathrm{~mm}^{2}$, waveguide cavity - backed transverse slot coupled feeding technique was used to maintain good radiation efficiency [14]. In dual-band PIFA of patch dimension $30 \mathrm{~mm} \times 40 \mathrm{~mm} \times 2 \mathrm{~mm}$, designed to operate at ISM 900 and Wi-Fi/ WLAN $915-928 \mathrm{MHz}$ frequencies, bandwidth of $2.2 \mathrm{KHz}$ and $3.5 \mathrm{KHz}$ respectively was obtained by adjusting the position of the feeding points and source [15].

To overcome the increasing demand for compact antenna with high bandwidth, it is discovered from the brief review of related previous works, that aside the complexity involved in most designs, the research interest of most electrically small antenna designers have shifted to higher band frequencies. This paper considers a relatively simple approach to bandwidth enhancement of compact PIFA for lower microwave $(900 \mathrm{MHz})$ frequency band. Specifically, a parametric study of PIFA is made and based on the study compact PIFA of volume $34 \times 17 \times$ $2 \mathrm{~mm}^{3}$ was designed and simulated. The bandwidth of designed PIFA was enhanced by increasing the distance between short plate and feed with the short placed at the edge of the width of patch, increasing the width of short and increase in distance between short and feed, without increasing the size, complexity and cost.

\subsection{Antenna Impedance Bandwidth (BW)}

Impedance bandwidth indicates the bandwidth for which the antenna is efficiently matched to its input transmission line such that $10 \%$ or less of the incident signal is lost due to reflection [16]. Its measurements include the characterization of the voltage standing wave ratio (VSWR) and return loss $\left(S_{11}\right)$ throughout the band of interest. It is the frequency range where the return loss is below a certain predefined level e.g. $-10 \mathrm{~dB}$ or $-6 \mathrm{~dB}$ which correspond to a power reflection of $10 \%$ and $25 \%$ respectively [17].

The impedance bandwidth of a narrowband antenna is defined as the percentage of the frequency difference over the center frequency $\left(f_{0}\right)$ given mathematically as [18]:

$$
\operatorname{BW}(\%)=\left[\frac{\mathrm{f}_{\mathrm{H}}-\mathrm{f}_{\mathrm{L}}}{\mathrm{f}_{0}}\right] \times 100
$$
(2) [19]:

Bandwidth depends on different parameters for a rectangular patch as shown in Equation

$$
B W(\%)=3.77 \frac{\epsilon_{r-1}}{\varepsilon_{r}^{2}} \frac{W}{L} \frac{h}{\lambda} h \ll \lambda
$$

The bandwidth can also be found using Equation 3 [18]:

$$
B W(\%)=\frac{f_{0}}{Q}=\frac{4 f_{0}^{2} h}{c \sqrt{\varepsilon_{r}}}
$$

KINETIK Vol. 4, No. 2, May 2019: 149-156 
It is clear from Equation 2 that the smaller the antenna volume on the scale of the wavelength, the lower the maximum attainable impedance bandwidth. Thus, downsizing an electrically small antenna is a size to impedance bandwidth trade-off.

\section{Parametric Study of PIFA}

The design of PIFA at frequency of $900 \mathrm{MHz}$ was done by means of equations drawn from transmission line model for electrically small antenna design. The designed PIFA was simulated using HFSS. Then parametric study of the antenna was conducted to find out the effect of variation of the key parameters on the bandwidth of PIFA. The PIFA was simulated using air substrate of dielectric constant equal to 1. Afterwards, the parametric study of PIFA for wireless applications at frequency of $900 \mathrm{MHz}$ was made by varying patch dimensions, ground plane dimensions, short size and position, feed size and position. In each case, the value of the bandwidth is calculated from the return loss curve and impedance bandwidth (BW (\%)) is calculated using Equation 1. The designed antenna (PIFA) was simulated using with the values of the parameters as length of ground plane $L_{g}=70 \mathrm{~mm}$, width of ground plane $W_{g}=40 \mathrm{~mm}$, length of patch $L_{1}=56 \mathrm{~mm}$, width of patch $L_{2}=28 \mathrm{~mm}$, substrate thickness $H=2 \mathrm{~mm}$, width of short plate $W=2 \mathrm{~mm}$ and distance between short and feed $D=5 \mathrm{~mm}$.

A parametric study of PIFA at frequency of $900 \mathrm{MHz}$ is made so as to discover parameters that can be optimized to enhance the bandwidth of a compact antenna. For effective comparison, values of bandwidth are computed from upper and lower frequencies corresponding to $S_{11}=0.1$ $\mathrm{dB}$ in the reference PIFA which can operate at GSM900 band. The procedure adopted for this parametric study is that in which one parameter is changed at a time and the effect of such variation on PIFA bandwidth is observed while all other parameters are kept constant. The following parameters are studied:

\section{Variation of Patch dimension of PIFA}

The values of $L_{g}, W_{g}, H, W$ and $D$ were kept constant while changes were made in the length $\left(L_{1}\right)$ and width $\left(L_{2}\right)$ of the patch to ascertain their effects on the performance characteristics of PIFA. The length $\left(L_{1}\right)$ of the patch is varied from $56 \mathrm{~mm}$ to $48 \mathrm{~mm}$ while width $\left(L_{2}\right)$ is varied from $28 \mathrm{~mm}$ to $36 \mathrm{~mm}$. The variations were made in such a way that the same overall dimension of the patch is maintained. The effect of patch configuration $\left(L_{1} / L_{2}\right)$ on bandwidth is shown in Figure 5.

\section{Variation of short size of PIFA}

While maintaining the values of the parameters for the reference antenna; $L_{g}=70 \mathrm{~mm}$, $W_{g}=40 \mathrm{~mm}, L_{1}=56 \mathrm{~mm}, L_{2}=28 \mathrm{~mm}, H=2 \mathrm{~mm}$, the width of the short plate (W) is varied from $1 \mathrm{~mm}$ to $16 \mathrm{~mm}$. The variation in bandwidth as the width is varied is shown in Figure 5 .

\section{Variation of Feed Size of PIFA}

By keeping constant the parameters of the reference PIFA, the width of feed $\left(L_{f}\right)$ was varied from $1 \mathrm{~mm}$ to $8 \mathrm{~mm}$ then width of feed $(33 \mathrm{~mm}$ ) higher than that of patch was also investigated and the resultant effect on bandwidth is presented in Figure 5.

\section{Variation of Feed Position of PIFA}

The effect of feeding position $\left(D_{\text {feed }}\right)$ on PIFA bandwidth was investigated by keeping the short plate close to the edge of the patch while varying the feed along the length of patch. First, the feed was place at $0 \mathrm{~mm}$ along the length of patch, then $2 \mathrm{~mm}, 5 \mathrm{~mm}, 10 \mathrm{~mm}, 20 \mathrm{~mm}$ while other parameters are the same as the reference antenna. The simulated result is shown in Figure 5.

\section{Variation of Short Position of PIFA}

Here, all possible positions of short with respect to feed were considered. Short position effect was investigated by keeping the feed position constant and varying the short position $\left(D_{s w}\right)$ along the width of the patch with all other parameters of PIFA remaining the same. Afterwards, short and feed positions $\left(D_{s f w}\right)$ were varied concurrently along the width of the 
patch with a distance (D) of $5 \mathrm{~mm}$ between them. The effects of these variations on bandwidth are shown in Figure 5.

\section{Variation of Ground plane Dimensions of PIFA}

Ground plane dimension effect was investigated in two ways: First, the length of the ground plane $\left(L_{g}\right)$ was kept constant at $70 \mathrm{~mm}$ and the width $\left(W_{g}\right)$ varied from $30 \mathrm{~mm}$ to $80 \mathrm{~mm}$ with other parameters unchanged. Similarly, the width was fixed at $40 \mathrm{~mm}$ and the length varied from $60 \mathrm{~mm}$ to $140 \mathrm{~mm}$. The results are shown in Figure 5.

\section{Results and Discussion}

The results of the simulated reference PIFA and parametric study carried out on the designed PIFA are presented as follows; Figure 1 and Figure 2 show the return loss and gain plot of the reference PIFA respectively. When the ratio of patch dimension $\left(\mathrm{L}_{1} / \mathrm{L}_{2}\right)$ is $2.0 \mathrm{~mm}$, the simulated PIFA had initial bandwidth of $120 \mathrm{MHz}$. As the ratio $\mathrm{L}_{1} / \mathrm{L}_{2}$ decreases, bandwidth increased as shown in Figure 5. On the other hand, as the bandwidth increases, resonance frequency increases linearly from $903 \mathrm{MHz}$ to $952 \mathrm{MHz}$ as presented in Figure 6. This is in agreement with theory since the resonance frequency depends on the dimensions of the patch as revealed by (3).

When the size of the short $(\mathrm{W})$ increased, the bandwidth increased then decreased beyond $4 \mathrm{~mm}$ width of short plate, however, the plot of impedance bandwidth against frequency (Figure 6) reveals that resonance frequency increased linearly with increase in width of short plate. At $8 \mathrm{~mm}$ and $16 \mathrm{~mm}$ width of short plate, the PIFA resonated at $1036 \mathrm{M} \mathrm{Hz}$ and $1160 \mathrm{MHz}$ frequencies respectively, both of which are above $960 \mathrm{MHz}$ upper limit of GSM900 frequency band.

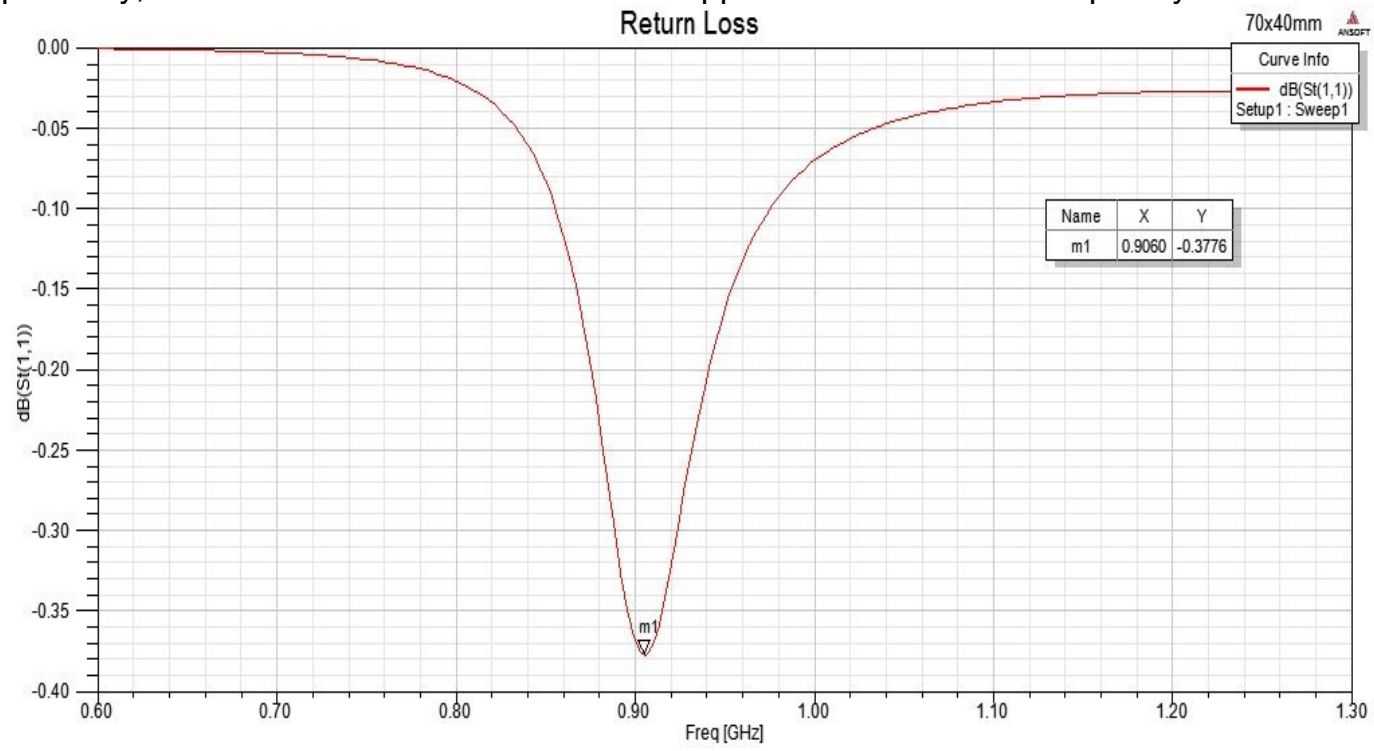

Figure 1. Return Loss of Reference PIFA

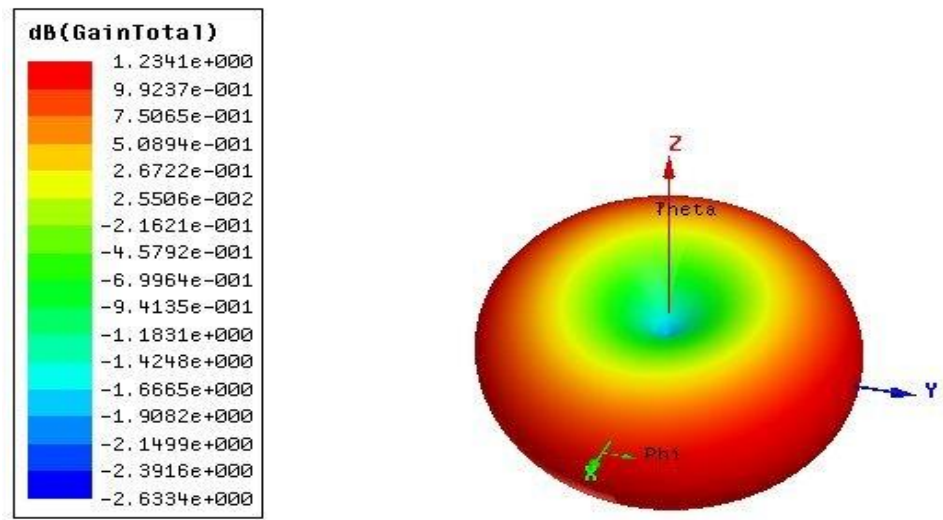

Figure 2. Gain Pattern of Reference PIFA

KINETIK Vol. 4, No. 2, May 2019: 149-156 
In Figure 6, the simulated result shows that no linear relationship can be established between the bandwidth and the resonance frequency as the feed size increased. Width of feed $L_{f}=33 \mathrm{~mm}$ did not give any reasonable return loss to enable the calculation of bandwidth because this width is higher than the width of patch hence some energy may have been lost. The result plotted in Figure 5 also shows that variation in the width of feed above $2 \mathrm{~mm}$ does not have any significant effect on the bandwidth of PIFA.

The simulated result of variation of feed position $\left(D_{\text {feed }}\right)$ with respect to a fixed short plate close to the width edge of patch reveals that increase in $D_{\text {feed }}$ affects the resonance frequency and bandwidth. PIFA bandwidth increased with increase in distance from the edge of the patch however, bandwidth dropped from $165 \mathrm{MHz}$ to $144 \mathrm{MHz}$ when the distance between the width edge of patch and the feed position increased from $10 \mathrm{~mm}$ to $20 \mathrm{~mm}$ (see Figure 5). The zero point on the plot of bandwidth against $D_{\text {feed }}$ in Figure 5 depicts the instant when the feed was placed at the same position with the short plate. At this point, matching problem occurred resulting in unsuccessful simulation. Increase in bandwidth led to increase in resonance frequency as shown in Figure 6. Maximum bandwidth of $165 \mathrm{MHz}(18.33 \%)$ was observed as the feed position approached the middle of patch width.

With the feed fixed at $5 \mathrm{~mm}$ length of patch, while the short is varied at $2 \mathrm{~mm}$ interval along the width of the patch, the resonance frequency and bandwidth increases with increase in distance between the short and the feed $\left(D_{s w}\right)$. The further away the short is from the feed, the higher the resonant frequency and the bandwidth as presented in Figures 5 and 6 . Figure 5 shows that as the short and the feed positions are varied concurrently along the width of the patch, increase in bandwidth resulted as distance $\left(D_{s f w}\right)$ of the short and feed widens. This variation resulted in a percentage increase in bandwidth of $41.67 \%$ at $8.0 \mathrm{~mm}$ distance between feed and short along the width of patch. Again, there is a linear relationship between bandwidth and resonance frequency (figure6).

Increase in bandwidth (BW) with increase in length of ground plane $\left(L_{g}\right)$ was observed through the parametric study. This variation actually gave the maximum increase in bandwidth of $180 \mathrm{M} \mathrm{Hz}(150 \%)$ more than the initial bandwidth of $120 \mathrm{MHz}$ (Figure 5). The resonance frequency is not very sensitive to the dimension of the length of ground plane as shown in the plot of impedance bandwidth versus resonance frequency (Figure 6).

The simulated result in Figure 5 shows that the bandwidth decreased with increase in width of ground plane $\left(\mathrm{W}_{\mathrm{g}}\right)$ but increased when the value of $\mathrm{W}_{\mathrm{g}}$ became larger than $\mathrm{Lg}_{\mathrm{g}}$ (i.e. at $80 \mathrm{~mm}$ ). In general, increase in width of ground plane did not show any significant effect on PIFA bandwidth. Consequently, though the resonance frequency decreased at some point, it is not very sensitive to variation of the width of the ground plane. This may be due to the fact that the antenna (patch) dimension is the dominant factor for radiation. Slight variation in resonance frequency with bandwidth was observed as shown in Figure 6.

From the foregoing, it can be seen that the bandwidth of PIFA is affected by size ratio of the planar element $\frac{L_{1}}{L_{2}}$, width and position of short plate, size and position of feed and variation in the size of the ground plane. However, bandwidth can only be enhanced by one or combination of the following ways:

1. reducing the size ratio of the planar element (patch) of PIFA,

2. increasing the distance between short plate and feed with the short placed at the edge of the width of patch,

3. increasing the width of short and increase in distance between short and feed,

4. increasing the length of ground plane while keeping the width of ground plane constant.

Nevertheless, in compact wireless systems, increasing the length of the ground plane may not be a good choice as this does not enhance miniaturization of PIFA. The results (Figure 6) also show that each of this parametric variation leads to either increase or decrease in resonance frequency, hence, care must be taken to ensure that the resonance frequency is maintained within the band of interest in order to avoid detuning.

Based on parametric study, a compact practical PIFA of ground plane size $56 \mathrm{~mm} \times 30 \mathrm{~mm}$ and patch size $34 \mathrm{~mm} \times 17 \mathrm{~mm} \times 2 \mathrm{~mm}$, and $20 \mathrm{MHz}$ bandwidth was obtained. The return loss and gain plots of the practical PIFA designed for GSM900 are shown in Figure 3 and 4. Table 1 gives the summary of the results of the work done by other researchers on badwidth enhancement of PIFA. The bandwidth obtained in this design is good considering the compactness and simplicity of design at low microwave frequency band. 


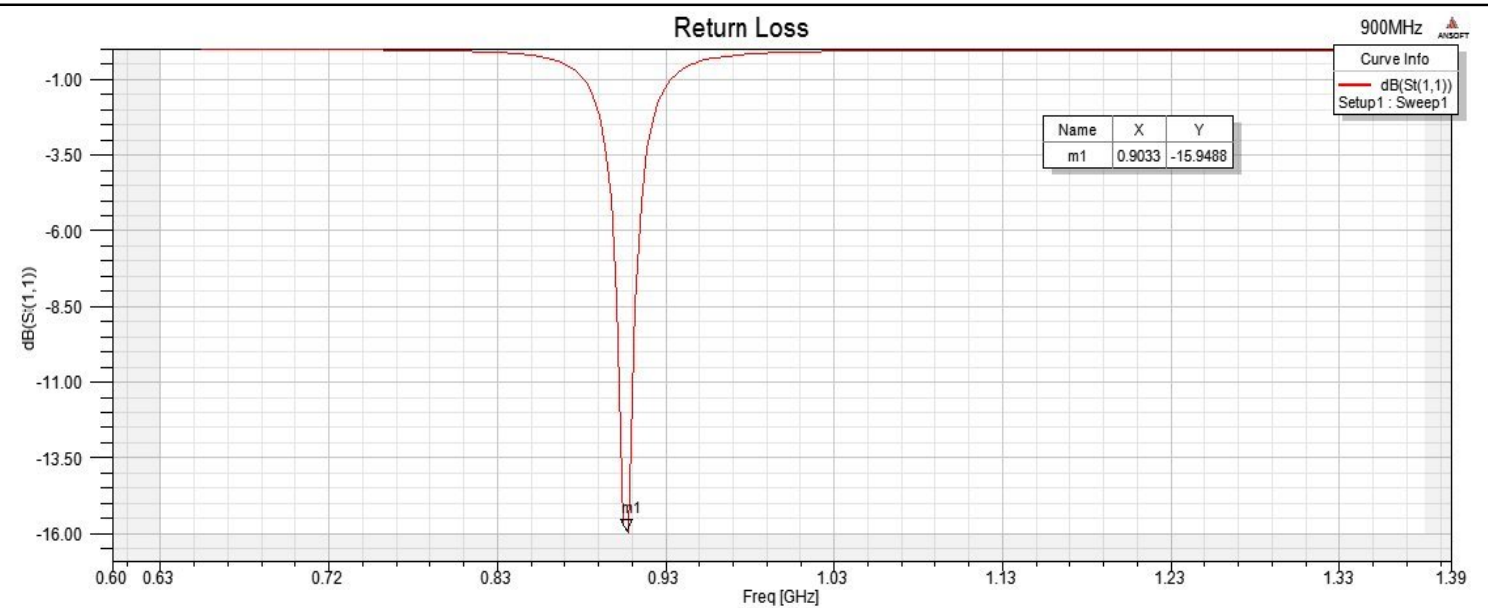

Figure 3. Return Loss of Compact PIFA

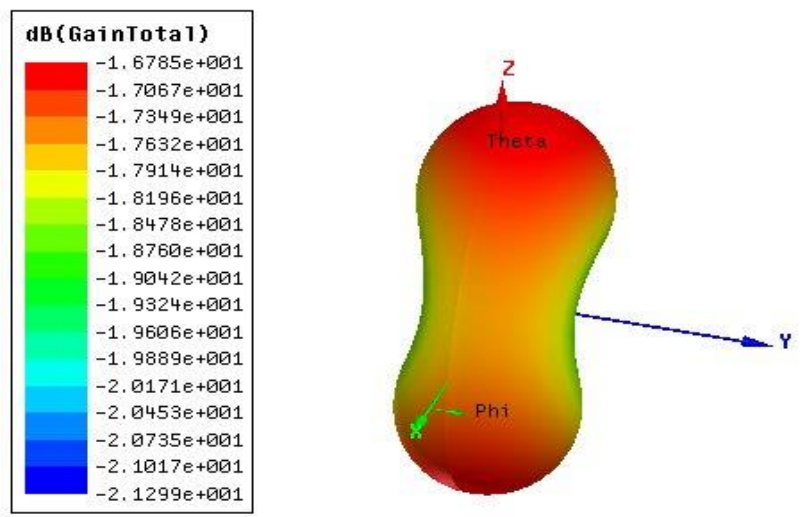

Figure 4. Gain Pattern of Compact PIFA
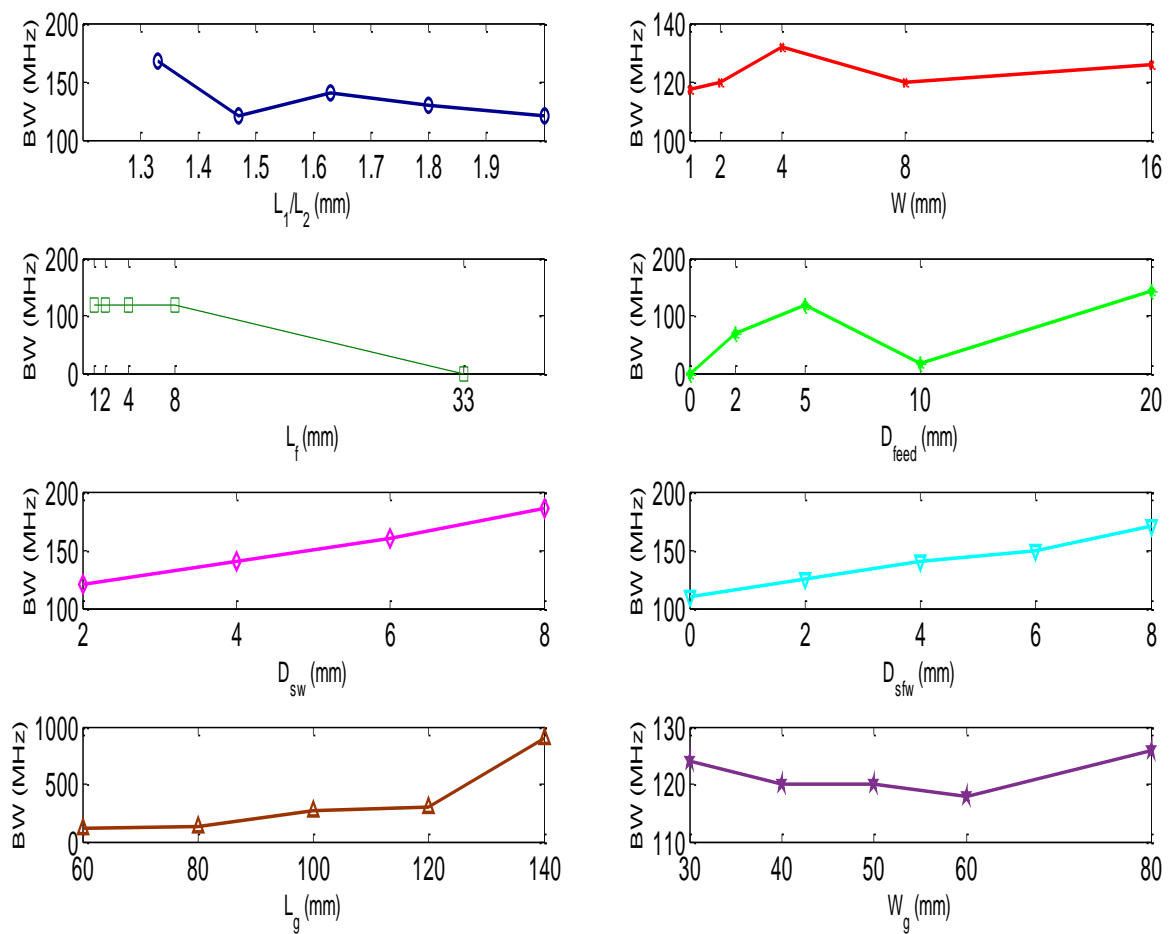

Figure 5. Plots Showing Relationship Between Bandwidth and Varied Parameters of PIFA

KINETIK Vol. 4, No. 2, May 2019: 149-156 


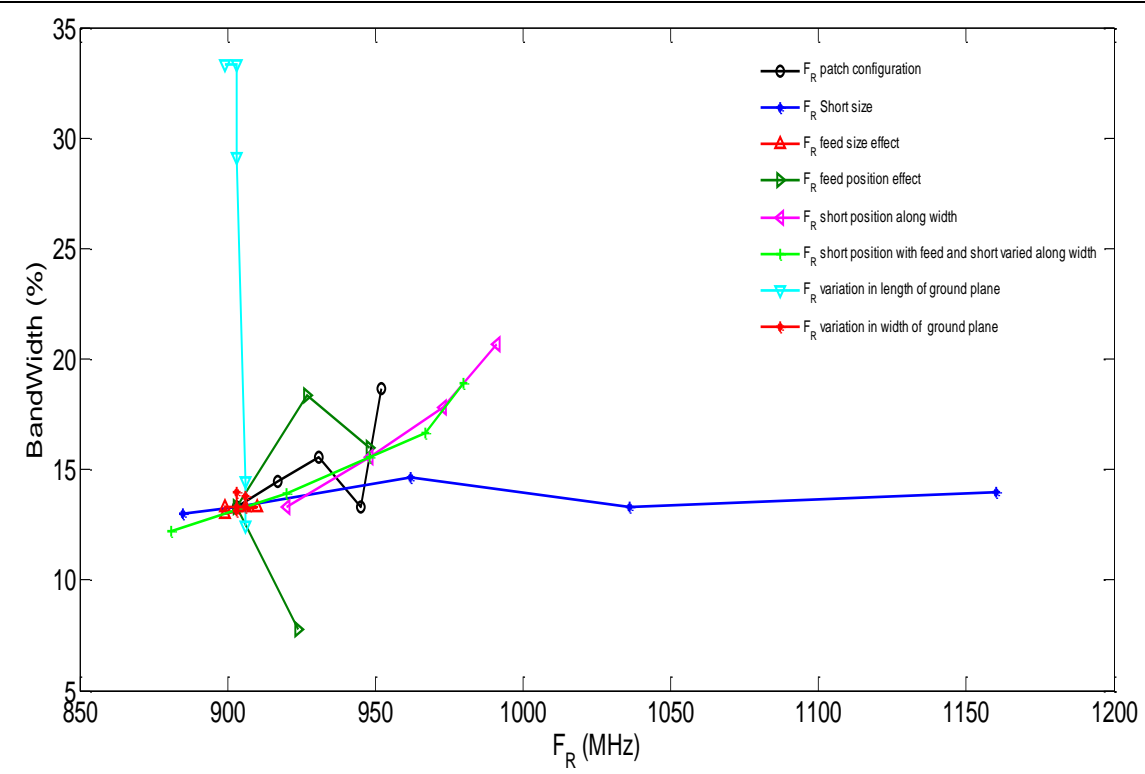

Figure 6. Graph of Impedance Bandwidth Against Resonance Frequency of All The Varied Parameters

Table 1. Comparison of Designed PIFA with Result of Previous Work

\begin{tabular}{|c|c|c|c|c|c|c|}
\hline \multirow[t]{2}{*}{ Ref. } & \multicolumn{2}{|c|}{ Antenna Size $(\mathrm{mm})$} & \multirow[t]{2}{*}{$\begin{array}{c}\text { Frequency } \\
(\mathrm{GHz})\end{array}$} & \multirow[t]{2}{*}{$\begin{array}{l}\text { Gain } \\
(\mathrm{dB})\end{array}$} & \multirow[t]{2}{*}{$\begin{array}{l}\text { Bandwidth } \\
(\mathrm{MHz}) / \%\end{array}$} & \multirow[t]{2}{*}{$\begin{array}{c}\text { Design } \\
\text { Complexity }\end{array}$} \\
\hline & $\begin{array}{l}\text { Ground } \\
\text { Plane }\end{array}$ & Patch & & & & \\
\hline [9] & $60 \times 30 \times 5$ & - & $\begin{array}{l}1.66-2.84 \\
3.36-3.64\end{array}$ & $2.0-4.0$ & $\begin{array}{c}52.44 \% \\
8.0 \%\end{array}$ & Complex \\
\hline$[10]$ & - & - & $3.3 \& 5.2$ & -9.95 & $\begin{array}{c}100 \& \\
300 \mathrm{MHz}\end{array}$ & Complex \\
\hline$[11]$ & $48.4 \times 19 \times 6.5$ & - & 2.92 & - & $200 \mathrm{MHz}$ & Complex \\
\hline [12] & $100 \times 60 \times 1.6$ & - & $1.2-3.0$ & $2.0-4.6$ & - & Complex \\
\hline [13] & $55 \times 20 \times 3$ & - & $1.6-3.6$ & 3.0 & $2000 \mathrm{MHz}$ & Complex \\
\hline$[14]$ & $72 \times 62$ & - & $3.0-6.0$ & - & - & Complex \\
\hline [15] & - & $30 \times 40 \times 2$ & $\begin{array}{c}0.9 \\
0.915-0.928\end{array}$ & 2.0 & $\begin{array}{l}0.0022 \mathrm{MHz} \\
0.0035 \mathrm{MHz}\end{array}$ & Simple \\
\hline $\begin{array}{l}\text { Our } \\
\text { design }\end{array}$ & $56 \times 30 \times 2$ & $34 \times 17 \times 2$ & 0.9 & -1.67 & $20 \mathrm{MHz}$ & Simple \\
\hline
\end{tabular}

\section{Conclusion}

By variation of dimensions and positions of the key components of the antenna, such as patch size, short size and position, feed size and position, as well as ground plane dimension, bandwidth of PIFA can be enhanced to as high as $300 \mathrm{MHz}(33.33 \%)$ or reduced to as low as $70 \mathrm{MHz}(7.78 \%)$. Increase in length of ground plane also increases bandwidth. However, for compact wireless systems, increase in length of ground plane contradicts the idea of miniaturizing the antenna to suit the limited available space for different components of the system hence, may not be employed. These simple and low cost approaches to bandwidth improvement can be employed in the design of PIFA for wireless systems operating at low Microwave frequency bands given such as GSM 850, GSM 900 and ISM 900.

The designed PIFA can be employed in wireless systems such as cell phone (GSM 900) and implantable medical devices (ISM 900) each with maximum impedance bandwidth of $7.78 \%$ and $2.89 \%$ respectively. The paper recommends that for effective application in wireless system, 
each of this simple and low cost method of bandwidth enhancement must be optimized through simulation so as to check detuning that could arise as a result of variation in the frequency associated with variation in the dimensions of each of the desired part of PIFA.

\section{References}

[1] A. K. Skrivervik, J. F. Ziircher, O. Staub and J.R. Mosig, "PCS antenna design: The Challenge of Miniaturization," IEEE Antennas and Propagation Magazine. Vol. 43, No. 4, Pp. 12-27, 2001.

[2] K. Mikko, "Bandwidth Enhanced Antennas for Mobile Terminals and Multilayer Ceramic Packages," Academic Thesis, Department of Electrical and Information Engineering, Faculty of Technology University of Oulu, Finland; pp. 1-86, 2009. http://herkulus.oulu.fi/issn03553213/

[3] F. Nariman and S. Mahmoud, "Planar Inverted F - Antenna (PIFA): Design Dissection for Cellular Communication Application," Journal of Electromagnetic Analysis and Application, Vol. 3, Pp. $406-411,2011$.

[4] S. Raghavan and N. Jayanthi, "Design of Planar Inverted -F Antenna for Wireless Applications," WSEAS Transactions on Communications, Vol. 8 No. 8, Pp. 863 - 872, 2009.

[5] Z. Xingyu and Z. Anping, "Enhanced-bandwidth PIFA Antenna with a Slot on Ground Plane," in PIERS Proceedings, Beijing, China, March 2009, Pp. 23 - 27.

[6] F. Wang, Z. Du, Q. Wang and K. Gong, "Enhanced-bandwidth PIFA with T-shaped Ground Plane", Electronics Letters, Vol. 40, Pp. 1504 - 1505, 2004.

[7] M. Kanchan, G. Deepak and J. Mohit, "Design of a Compact PIFA for PCS Applications". Unpublished article of Department of Electronics and Communication Engineering, Indian Institute of Technology, Guwahati (India).

[8] W. Kin-Lu and H. Chih-Hong," Bandwidth-Enhanced Internal PIFA with a Coupling Feed for Quad-band Operation in the Mobile Phone". Microwave and Optical Technology Letters, Vol. 50, No. 3. 2008, DOI: $10.1002 / \mathrm{mop}$.

[9] C. Suárez, R. Rodríguez and M. F. Bataller, "Broadband Planar Antenna with Improved Pattern Bandwidth," Revista Faculted de Ingeniera Universidad de Antioquia no. 65 Medellín, 2012.

[10] R. Sayyed and B. Patil, "Bandwidth Enhancement in Dual Band PIFA by Parasitic Element," International Journal of Advanced Research in Electrical Electronics and Instrumentation Engineering, Vol. 4, No.11, Pp. 9293 - 93000, 2015.

[11] P. K. Dhurvey and P. Jain, "Bandwidth Enhancement for PIFA Antenna Using Circular Slot in Radiating Patch and Ground Plane for Wireless Communication," International Journal of Advanced Research in Electrical, Electronics and Instrumentation Engineering, Vol. 4, No. 8, Pp. $6929-6934,2015$.

[12] M. Naser-Moghadasi, Z. Mansouri, S. Sharma, F. B. Zarrabia and B. S. Virdee, "Low SAR PIFA Antenna for Wideband Applications" IETE Journal of Research, Pp. 1 - 7, 2016.

[13] H. T. Chattha, M. Nasir, Q. H. Abbasi, Y. Huang and S. S. Aljaafreh, "Planar Inverted-F Antenna for Universal Serial Bus Dongle Applications," Turkish Journal of Electrical Engineering \& Computer Sciences, Vol. 25. Pp. 4280 - 4286, 2017

[14] B. Muneer, W. Shabur and F. K. Shaikh, "Plate - Laminated Slotted - Waveguide Fed $2 \times 3$ Planer Inverted F Antenna," International Journal of Electronics and Communication Engineering, Vol. 11, No.1, Pp. $129-132,2017$.

[15] V. Preethi and S. A. Devi, " PIFA Antenna for Wireless Communications," International Journal of Engineering and Techniques, Vol. 4, No. 3, Pp. 646-648, 2018.

[16] J. Powell, "Antenna Design for Ultra Wideband Radio". M.Sc. Thesis. Massachusetts Institute of Technology, Cambridge, 2004.

[17] F. Gustrau and D. Manteuffel, "EM Modeling of Antennas and RF Components for Wireless Communication Systems". Springer Verlag, Germany, pp. 48 - 54, 2006.

[18] T. Edling, "Design of Circular Polarized Dual Band Patch Antenna". M.Eng. Thesis Uppsala University, 2012.

[19] R. Garg, Microstrip Antenna Design Handbook. Artech House Inc., Boston, 2001. 